\title{
Service-delivery Strategies:
}

\section{Three Approaches to Consulting for Hospitality}

\begin{abstract}
Effective consulting for hospitality involves going beyond applying mere expertise to solve a client's particular problem to being an empowering expert who focuses on ensuring that clients obtain the tools and resources needed to solve their own problems.
\end{abstract}

BY KATE WALSH

$\mathrm{H}$ ospitality managers and executives frequently retain consultants to assist with specific projects or perform specialized tasks, ranging from conducting feasibility studies to implementing IT systems. Often in making the decision about whom to retain, managers must rely on a résumé, references, or even a "gut feel" for which consultant would be best. The choice is complicated by the fact that different consultants take different approaches in performing their assignments. While it would make sense for a manager to retain a consultant whose operating style is a good fit, little research exists regarding what approaches professional consultants use to deliver a product or service-that is, the consultants' client-related strategies. As a result, little information exists to guide managers decision making.

This study sought to fill that void by examining the espoused operating styles of 50 partners, high-level directors,

C 2002, CORNELL UNIVERSITY and managers of three of the former big-five accounting firms. These professionals worked in the areas of audit, taxation, and general business consulting-and many of them performed services for hospitality organizations. As described in this article, I found three identifiable service-delivery strategies. To frame this study's findings, I briefly review relevant research on professional service delivery and discuss the mixed picture created by past research studies.

\section{Research on Service Relationships}

In the 1980 s organizational researchers began to focus serious attention on how services are delivered. They found that services are vastly different from manufacturing in that (1) the product for sale is an intangible experience that cannot be possessed;' (2) the product is simultaneously produced and

${ }^{1}$ D.E. Bowen and B. Schneider, "Services Marketing and Management: Implications for Organizational Behavior," Research in Organizational Behavior, Vol. 10 (1988), pp. 43-80. 
EXHIBIT 1

\section{Classic service-delivery strategies}

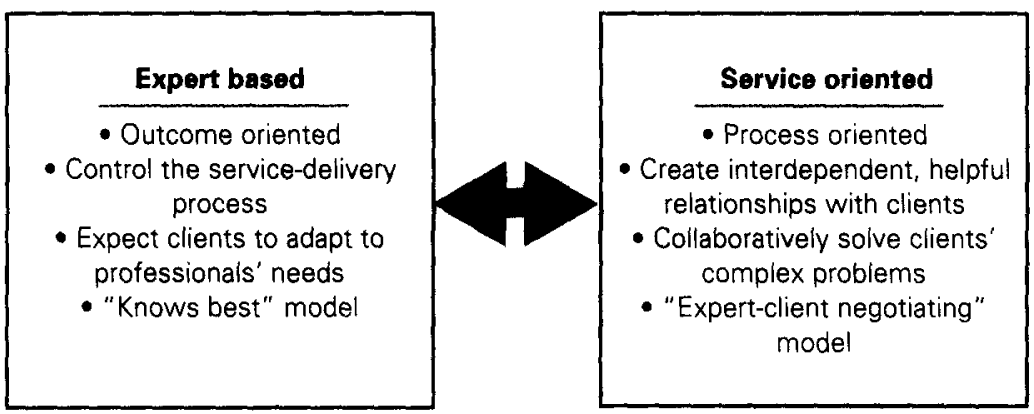

Research implies that service professionals' actions fall along a continuum in their service-delivery strategies, as shown here. The expertise-based strategy calls for controlling the delivery process and expecting clients to adapt to the consultant's needs and style. Other consultants essentially become partners with their clients and collaborate in solving the client's problems. consumed; ${ }^{2}$ and (3) the customer plays a key role in creating and consuming the product for sale. ${ }^{3}$

Within this framework, professional services generally involve the creation of long-term, ongoing relationships with clients. These long-term relationships are distinguished by their repeated interactions that enable professionals to garner knowledge about their clients' specific needs over time, and thereby create a more-efficient process of interacting to deliver a more-effective, customized service.

\section{Ways to Connect with Clients}

Providing a professional service of the kind I just discussed means that the provider offers some form of expertise to the client, for example, legal advice, marketing savvy, or tax knowledge. In examining past studies, I found that researchers offer conflicting arguments about the best way to deliver this expertise. On the one hand, some researchers propose that connecting and building relationships with clients is essential. ${ }^{4}$ On the other hand, others suggest that remaining (emotionally) detached from the client and even conveying arrogance is critical to delivering professional work. ${ }^{5}$ As an example of the first approach, nurses are usually taught that it is critical to connect on both a cognitive and emotional level with their parients. ${ }^{6}$ In contrast, lawyers are taught that arrogance and intimidation are signals of expertise, and they are encouraged to use games-

\footnotetext{
${ }^{2}$ D.E. Bowen and T.G. Cummings, "Suppose We Took Service Seriously?," Service Management Effectiveness, ed. D.E. Bowen, R.B. Chase, and T.G. Cummings (San Francisco: Jossey-Bass, 1990), pp. 1-12.

${ }^{3}$ L. Argote, "Input Uncertainty and Organizational Coordination in Hospital Emergency Units," Administrative Science Quarterly, Vol. 27 (1982), pp. 420-434.

${ }^{4}$ N. Noddings, Caring: A Feminist Approach to Ethics and Moral Education (Berkeley, CA: University of California Press, 1984).

${ }^{5}$ See: J. Pierce, "Rambo Litigators: Emotional Labor in a Male-dominated Occupation," in Masculinities in Organizations, ed. C. Cheng (Thousand Oaks, CA: Sage Publication, 1996), pp. 1-28; and J. Pierce, Gender Trails: Emotional Lives in Contemporary Law Firms (Berkeley, CA: University of California Press, 1995).

${ }^{6}$ See, for example: P. Benner, Novice to Expert: Excellence and Power in Clinical Nursing Practice (Menlo Park, CA; Addison-Wesley, 1984); and P. Benner and J. Wrubel, The Primacy of Caring: Stress and Coping in Health and Illness (Menlo Park, CA: Addison-Wesley, 1989).
} 
manship to dominate others. ${ }^{7}$ So, too, one study found that insurance salesmen were encouraged to be aggressive, dominant, and manipulative when "outmaneuvering" potential prospects or clients. ${ }^{8}$

\section{Implications for Service-delivery Strategies}

Previous research implies that service professionals' actions fall along a continuum in their service-delivery strategies (see Exhibit 1). There are those who adopt an expertise-based strategy, by controlling the delivery process and expecting clients to adapt to their needs and style. In contrast, there are those who essentially become partners with their clients and collaborate in solving the client's complex problems. ${ }^{9}$

The expertise-based strategy might be adopted by a world-renowned physician who keeps clients waiting for hours and is quite abrupt in his manner, but who is so skilled at what he does that clients accept his approach, as well as his answers. In fact, more than 50 years ago researchers suggested that because professionals apply their abstract knowledge to solve complex problems-knowledge that can only be obtained through years of extensive study, training, and hands-on experience, ${ }^{10}$ they hold uncontested authority over their clients ${ }^{11}$ and often know their clients' needs better than their clients themselves do. With an expert-based approach, service professionals "translate the clients' desires into a professional metalanguage or explain to clients what is possible in their situations." 12

\footnotetext{
7 See: Pierce, 1996; and Pierce, 1995.

${ }^{8}$ R. Leidner, Fast Food, Fast Talk: Service Workers and the Routinization of Everyday Life (Berkeley: University of California Press, 1993).

${ }^{9}$ For example, see: Judi Brownell and Dennis Reynolds, "Strengthening the F\&B Purchaser-Supplier Partnership: Actions that Make a Difference," on pages 49-61 of this Cornell Quarterly.

${ }^{10}$ See: A. Abbott, The System of Professions (Chicago: University of Chicago Press, 1988).

${ }^{1}$ A. Carr-Saunders and P.A. Wilson, The Professions (Oxford: Clarendon Press, 1941).

12 G. Hanlon, "A Shifting Profession: Accountancy," in The End of the Professions? The Restructuring of Professional Work, ed. J. Broadbent, M. Dietrich, and J. Roberts (London: Routledge, 1997), p. 125.
}

The second strategy is akin to a serviceoriented consultant who views consultations as "client-centered partnerships." Within this framework, service professionals create interdependent, helpful relationships with clients ${ }^{13}$ where "one human system intervenes so that another human system perceives that it is or has been helped."14 Several researchers argue that this type of part-

\section{Researchers have identified two general strategies for delivering consulting services-expert and the service oriented. This study outlines a third strategy.}

nership model is critical to the success of many consulting practices. ${ }^{15}$ Along that line, service professionals from financial planners to doctors are encouraged to replace a "knows best" model of service delivery with an "expert-client negotiating" model. ${ }^{16}$ This study sought to determine the extent to which consultants use either of the above or other strategies to deliver their expertbased service.

\section{Studying Consultants}

As part of a larger study examining the role of organizational identity on service delivery, this study examined the strategies employed by 50 professionals at three of the former big-five public-accounting firms. These 50 respondents are directly responsible for generating and man-

\footnotetext{
${ }^{13}$ C. McGivern, "Some Facets of the Relationship between Consultants and Clients in Organizations," Journal of Management Studies, Vol. 20 (1983), pp. 367-386.

${ }^{14}$ C. Lundberg, "Towards a General Model of Consultancy," Journal of Organizational Change Management, Vol. 10 (1997), p. 200.

${ }^{15} \mathrm{M}$. Alvesson, "Organization as Rhetoric: Knowledgeintensive Firms and the Struggle with Ambiguity," Journal of Management Studies, Vol. 30 (1993), pp. 997-1019.

${ }^{16}$ See: M.R. Haug, "Elderly Patients, Caregivers, and Physicians: Theory and Research," Journal of Health and Social Behavior, Vol. 35 (1994), pp. 1-14; and T. Olvio, "Why Your Clients Selected You: The Good News Is, Clients Are Buying the Advisor Concept. The Bad News Is, Advisors Spend Too Much Time Talking and Not Enough Time Listening," Financial Planning, September 1, 1998, pp. 107-108.
} 
EXHIBIT 2

\section{Interview protocol}

\section{How do you view your role?}

(1) What do you think your clients expect from you?

(2) Please finish the following statement, listing as many descriptors as necessary: "As a consultant, I am..."

(3) What is the purpose of your work?

(4) What are the most important qualities and skills a consultant should possess?

(5) Why do you think your clients seek you out, as opposed to another professional?

\section{How do you demonstrate your role?}

(6) How do you demonstrate your expertise to your clients?

\section{How do you view your clients?}

(7) Describe your typical clients. How sophisticated and knowledgeable are they?

(8) What do you expect from your clients? What is their job, if any?

(9) Do you see yourself as dependent on your clients? Why or why not?

(10) What, if anything, do your clients teach you?

\section{Data Collection and Analysis}

This research is based on the question: What strategies do service professionals use to deliver their expert-based service? To do so, I conducted in-depth, structured interviews with all 50 respondents (see Exhibit 2). My intent was to uncover the different strategies service professionals both implicitly and explicitly use to serve clients. Interviews, on average, lasted between 60 and 90 minutes. With respondents' permission, 48 of the interviews were tape-recorded and immediately transcribed. To the degree possible, I employed copious note taking with the remaining two interviews and elaborated upon my notes immediately afterward.

When all interviews were transcribed to text, I analyzed each one and coded respondents' answers, a process formally termed "content analysis." In doing so, I created a coding schema. I then grouped codes into key categories represented by 10 percent or more of respondents. When all categories were defined, I went back and re-checked my coding scheme, looking for any missing information. Key categories were collapsed into major themes that emerged from the data. To check my interpretations, I had a second rater, trained in the method of content analysis, go through each interview and code the data. We agreed on 83 percent of the coding categories. In those areas where we disagreed, we were able to reach consensus. I then reviewed my results with ten of the respondents, checking for accuracy of understanding and credibility of my findings. $-K . W$. aging a client base and its associated revenues. Thirty-four respondents (68 percent) were fulllevel partners of their firms and the remaining 16 were high-level directors on the partner track who were responsible for their own cadre of clients. Fourteen ( 28 percent) of the 50 respondents were women, and five of these women were full partners. Thirty-five of the respondents ( 70 percent) were generally involved in the consulting end of the practice and the remaining 15 were involved in audit and tax work. Each respondent was asked a series of questions based on the protocol in Exhibit 2. The goal of the interviews was to uncover respondents' thoughts about (1) the roles that they play with clients, (2) ways in which they demonstrate their expertise to their clients, and (3) their views about their clients. Answers to each question were coded, analyzed for categories, and collapsed into the key themes I discuss next. For more information on data collection and the analyses used in this study, see the box at left.

\section{Common Characteristics}

The study's results suggest that, in fact, service professionals do deliver their service in both an expert-based and service-oriented manner and with varying degrees of weighting on the two. In addition, a third service-delivery strategy emerged from the data. Before explaining these findings in greater detail, I first offer some common characteristics held by these consultants.

The value of experience. Forty-five of the 50 respondents commented that without experience, consultants do not have much to offer clients. Experience provides the necessary training and expertise that enables consultants to offer their assistance. Experience relates mostly to exposure to their clients' industries and preferably their jobs, and is the source of their expertise. As one respondent commented, "I could never conceive of being a consultant right out of college. I feel pretty comfortable [doing it now], having been in the business 25 years before I decided to try and be a consultant." Another said, "If you don't know what you are doing and you don't have industry knowledge, you don't even get to play. That [industry knowledge] is a prerequisite. ...That's what allows you to run the race." When asked about important qualities and skills, 
EXHIBIT 3

Summary of how consultants view their role

\begin{tabular}{|c|c|c|c|c|c|}
\hline Possible work roles & $\begin{array}{l}\text { (1) What do } \\
\text { cliente expeat } \\
\text { from you? }\end{array}$ & $\begin{array}{l}\text { (2) I am the } \\
\text { client's } \\
\text { what? }\end{array}$ & $\begin{array}{l}\text { (3) What is the } \\
\text { purpose of } \\
\text { your work? }\end{array}$ & $\begin{array}{l}\text { (4) What are the } \\
\text { important } \\
\text { qualities and } \\
\text { skills? }\end{array}$ & $\begin{array}{l}\text { (5) Why do } \\
\text { oflents } \\
\text { you oft? }\end{array}$ \\
\hline The expert & $\begin{array}{l}\text { Share yout } \\
\text { expertise }(52 \%)\end{array}$ & $\begin{array}{l}\text { Advisor or prob- } \\
\text { lem solver }(58 \%)\end{array}$ & $\begin{array}{l}\text { To advise clients } \\
\text { and solve their } \\
\text { problems }(54 \%)\end{array}$ & $\begin{array}{l}\text { Their own } \\
\text { expertise }(40 \%)\end{array}$ & $\begin{array}{l}\text { Their own } \\
\text { expertise and } \\
\text { experience }(44 \%)\end{array}$ \\
\hline $\begin{array}{l}\text { The service-oriented } \\
\text { partner }\end{array}$ & $\begin{array}{l}\text { Attend to their } \\
\text { needs }(28 \%)\end{array}$ & $\begin{array}{l}\text { Helper, friend, } \\
\text { or ally }(22 \%)\end{array}$ & $\begin{array}{l}\text { To assist cients } \\
\text { with their } \\
\text { problems }(26 \%)\end{array}$ & $\begin{array}{l}\text { Client-service } \\
\text { skills }(30 \%)\end{array}$ & $\begin{array}{l}\text { The level of atten- } \\
\text { tion they give the } \\
\text { client }(26 \%)\end{array}$ \\
\hline $\begin{array}{l}\text { The empowering } \\
\text { expert }\end{array}$ & $\begin{array}{l}\text { Apply your } \\
\text { expertise to your } \\
\text { client's noeds } \\
(12 \%)\end{array}$ & $\begin{array}{l}\text { Coach, support, } \\
\text { guidance giver, } \\
\text { link, and liaison } \\
(16 \%)\end{array}$ & $\begin{array}{l}\text { To ensure the } \\
\text { client succesds } \\
(14 \%)\end{array}$ & $\begin{array}{l}\text { Developing an } \\
\text { awareness for } \\
\text { useful information } \\
(14 \%)\end{array}$ & $\begin{array}{l}\text { No one else } \\
\text { understands the } \\
\text { client or works } \\
\text { as hard for them } \\
(10 \%)\end{array}$ \\
\hline
\end{tabular}

one consultant suggested "the ability to convey years of experience into a quantifiable consulting product."

The value of individual reputation. A second characteristic, mentioned by 64 percent of respondents $(n=32)$, is that they believe their clients hired them for their individual reputation and expertise, as opposed to their firm's. Many discussed the reputation they have created for themselves, a reputation they believe would follow them if they ever joined another firm. As one respondent said, "A lot of these engagements are folks whom I knew; as soon as I was available to be a consultant they asked me to work for them. They wouldn't have cared if I was independent or part of [this firm]." Another said, "My clients told me, "we don't care whose name is on the letterhead, as long we get you.' That's what the investment in the relationships has gotten me. Their loyalty in me." Still another commented, "One of the things that has plagued us through the years is that for the rainmakers, the practice leaders, the partners, and the directors, the level of activity is directly related to the amount of personal marketing and practice development that they do." The conundrum for these types of consulting practices is that they count on their partners to bring in business, yet clients are often more loyal to the partners than to the practice.

\section{Roles Consultants Play}

Despite the fundamental similarities that I just outlined, I found distinctly different views on service-delivery strategies among the respondents. When asked a series of questions aimed at uncovering the role that they play with their clients, the consultants' responses fell into three themes (see Exhibit 3). ${ }^{17}$ Some respondents do see themselves as experts who impart knowledge to their clients and, in doing so, solve their clients' problems. An expert of this type would view

${ }^{17}$ Some respondents provided more than one answer that fell into at least two themes, and others provided answers that were not representative of the sample. 
EXHIBIT 4

\section{Summary of how consultants demonstrate expertise}

(6) How do you demonstrate your expertise to your clients?

\section{Terms that describe category and percentage of respondents that used these terms}

Demonstrate your expertise through ways you share information $(60 \%)$

\section{Meaning of category}

Includes beginning conversations with clients with a general question or two and then sharing information to impress the client with knowledge and expertise.

Includes asking specific questions at the beginning of client conversations that get at the heart of the client's business strategy or personal concerns.

EXHIBIT 5

\section{Summary of how consultants view their clients}

\section{(7) How sophisti- cated and knowledge- able are your clients?}

\section{(8) What do you expect from your clients?}

The expert:

Mixed; some are, and some are not $(40 \%)$

Act in a manner that demonstrates respect $(46 \%)$

\section{The service- oriented partner: \\ Provide access to Very $(30 \%)$ themselves and to information $(38 \%)$}

\section{The empowering expert:} (30\%)
Not at all

\section{(9) How depen- dent are you on your clients?}

\section{(10) What, if anything, do clients teach you?}

Clients don't teach us much, but we take away some information from all projects

$(52 \%)$ Independent or partially independent from clients $182 \%)$

(1)

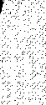

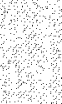

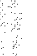

his or her role as the advisor or problem-solver to the client. These professionals believe that clients expect them to share their expertise. In fact, they believe that their expertise and experience are the reasons clients seek them out over other professionals.

Some respondents also think of themselves as the client's service-oriented partner, who works to create a helpful relationship with the client. While these individuals in no way lack the requisite expertise, service-oriented consultants believe that their clients expect them to attend to the clients' needs in things both large and small. These respondents see themselves as the client's helper, friend, or ally, and the primary purpose of their work is to assist clients in solving their problems. These consultants believe that their client-service skills are what distinguish them from their competitors, and they believe that they provide a level of attention to the client and the client's needs that surpass the level offered by their competition.

Something new. The results also revealed something new - a view that was actually part of an approach uncovered through this research (and further discussed in the next section). Some respondents think of themselves as "empowering experts" who apply their expertise in a focused, intentional, and savvy manner to make their clients succeed. These respondents see themselves as the client's empowering coach. The purpose of their work is to ensure that their clients achieve whatever goals they may have set. These respondents believe that their focus on and approach to understanding their clients are what distinguish them from their competitors. Critical skills for these respondents include creativity and developing an eye for useful information that the client may need.

\section{Demonstrating Expertise}

Regardless of their service strategy, the respondents in this study indicated that it is important to signal their expertise to their clients. What is interesting is the way in which they do so. Sixty percent of the respondents believe that they signal their expertise by demonstrating their depth of knowledge and by explaining the scope of their services. They do so through controlling client interactions with talk early in the client meeting 
and they often begin by outlining (selling) their many services-typically, using graphics and visual aids. Alternatively, 10 percent of the respondents reported they demonstrate their expertise by asking thoughtful, strategy-based questions early in the client interaction. The rationale behind using this tactic is that by getting clients to focus quickly on important issues, respondents use both their clients' and their own time more efficiently. In addition, the consultants (1) quickly learn about central issues, (2) demonstrate that they understand the importance of these issues to their clients, and (3) empower the clients to more fully control the conversation. Respondents believe that this approach better enables them to demonstrate their skill and simultaneously help their clients. The remaining 15 respondents reported using no specific strategy to demonstrate expertise, or ones that were not representative of the sample.

\section{Consultants' Views of Their Clients}

When asked about their views of clients, respondents' answers fell primarily into two or three different categories, depending on the question (see Exhibit 5). ${ }^{18}$ When asked about their clients' levels of sophistication and knowledge, the respondents' answers fell into roughly equal categories, with 30 percent of the respondents reporting that their clients were very knowledgeable, 30 percent reporting not knowledgeable, and 40 percent reporting somewhere between those extremes. When asked whether clients can teach consultants new things, more than half of the respondents thought that their clients could not teach them anything new, while the remainder felt they could.

Answers to questions about consultants' expectations of their clients and consultants' level of dependency on clients were more skewed. Forty-six percent of respondents reported that they expect clients to demonstrate respect, 38 percent reported that they expect their clients to provide access to information, and 10 percent reported expecting clients to demonstrate loyalty. Answers to issues of dependency were quite

\footnotetext{
${ }^{18}$ With the exception of an empowering-expert approach, it was difficult to group categories of these answers into specific themes.
}

skewed. Eighty-two percent of respondents reported they see themselves as mostly independent from their clients, while only 14 percent of respondents see themselves as dependent on their clients.

\section{Service-delivery Strategies}

Taken together, these findings reveal three strategies that professional consultants typically use to deliver their service. ${ }^{19}$ Consonant with the literature, ${ }^{20}$ more than half of the respondents in this study approach service delivery as an expert imparting knowledge to a client. As mentioned, 90 percent of the respondents believe that their experience is essential to the work they do. In addition, 52 percent of respondents believe that clients expect them to share their expertise, and 44 percent of the respondents believe their clients seek them out because of it. In sharing that expertise, respondents in this study act as either the client's advisor or problem solver. They see this role as the source of their success, guiding the way they control client interactions.

Approximately one-third of respondents approach service delivery through combining their expertise with their client-service skills. These respondents tend to think of themselves as the client's service-oriented partner, and they attend to their clients' needs through forming a partnership. Unlike a completely equitable partnership, as suggested in the consulting literature, ${ }^{21}$ these service professionals view their primary responsibility as maintaining and managing the relationship, more so than the client does. They respond to clients' questions and concerns, regardless of how time-consuming, and they see thernselves as the client's helper, friend, or ally. Overall, these respondents believe their clientservice skills help distinguish them from other

\footnotetext{
${ }^{19}$ As mentioned, many respondents' answers fell into multiple categories (e.g., a professional who views himself as both an expert and consulting partner and clients as being both active and passive), making it difficult to assess which professionals used which strategies. Nevertheless, the data presented discernable themes.

${ }^{20}$ For example, see: Abbott, op. cit.

${ }^{21}$ For example, see: McGivern, op. cit.; and J. Waclawski, A.H. Church, and W.W.Burke, "Women in Organizational Development," Journal of Organizational Change Management, Vol. 8 (1995), pp. 12-22.
} 
EXHIBIT 6

Comparison of consulting strategies

\section{Empowering expert}

More-traditional strategies

Empower the client

Advise the client

\begin{tabular}{ll}
\hline Learn from the client & Take away knowledge from the project \\
\hline Interdependent with client ("we") & Independent from client ("me")
\end{tabular}

Ask questions and listen

Tell information professionals, and they use client interactions to sell their focused service.

\section{The Empowering Expert}

This study also revealed that six respondents employ a strategy different from either of those just discussed. ${ }^{22}$ These consultants determine the central issue that will make a particular client successful, and they act as the behind-the-scenes coach to allow their client to champion and implement the idea. These consultants use their creativity to constantly feed new ideas to their clients, hoping something will help, while also working to ensure that their clients "look good" in the eyes of their boss or professional community. These consultants believe that the way in which they apply their expertise to help the client individually succeed leads to their own success. The strategy that they use is defined by four major characteristics that are also summarized in Exhibit 6. Next, I describe and contrast this "empowering expert" strategy with the moretraditional expert-based and service-oriented strategies.

\footnotetext{
22 These six consultants, who were members of two of the three firms who participated in this study, provided consistently similar answers that mirrored the same categories across each question. In other words, their views about their role, the ways they demonstrate their expertise, and their views of clients were similar in most, if not all, questions. This enabled me to cleanly draw a profile of this specific approach to service delivery.
}

\section{Empowerment versus Advice}

The first characteristic of an empowering-expert strategy is a desire to infuse the client with knowledge and skills that contribute to his or her personal success. Consultants who employ this strategy provide personal support to their clients and call themselves the client's coach. As one respondent said, "What I do is let them know that I understand what their position is in the company, that I am aware of what risks they are taking by embarking on some of these projects, and that I'm going to do everything in my power, single-mindedly, to make sure that they come out as heroes in their own business group." Additionally, another consultant stated: "If I'm working on a chain of coffee houses, I will save clippings and do research on coffee-house trends, new food and beverage product lines, and new store designs. That is not part of the deliverables of my project written in any contract, but it allows me to communicate continuously, build a relationship, and provide information to the client so that he or she knows that-even though something is not part of the specific scope of the work-I'm thinking of them and I want them to get smart." Along that line, a third respondent said, "My strategy is different from any other partner here. I figure out the one thing my client needs to do his job well, and I give him the tools or information to do it. I'm the behind-the-scenes person, and my client is the one who looks good."

In contrast, the more-traditional expert-based strategy is to advise the client. Consultants who adopt the role of advisor believe that their job is to use their experience and expertise to provide clients with the answers to their problems. As an example, one respondent explained, "Clients expect someone who can articulate 30 years of experience in the business and translate it into telling them something they don't know about the business." Another said, "All of our clients are looking for experts... somebody to stand up and tell the audience what the right answer is.... They need someone else with the credibility to come in and sell it to their boss... They're all looking to you for your expertise." Still a third respondent commented, "We're advisors. ...Clients come in and say, 'how do we get from here to there?" More than half ( 54 percent) of respondents spoke of their work as solving clients' prob- 
lems. They believe that if they solve the problem well, clients will continue to use them for additional projects.

\section{Learning from the Client}

A second distinct feature of an empoweringexpert strategy is the belief that clients can teach consultants new things. As one respondent commented, "I always learn so much from my clients, usually about their specific primary drivers." Another discussed different things that his clients teach him. He said, "One of my clients is the new president in a company that's private now but wants to go public. He and I have talked a lot about the IPO issues [discussed by] his board of directors, and how he got his financing. I don't advise him on any of that, but he is just telling me all about those things, so I've learned a lot about it." A third respondent described the collaborative nature of consulting: "I look upon it as they [the clients] know something we don't, and we know something they don't, but we know a bit about what each other does so you combine [that knowledge].... You both end up learning, and you both end up getting things done." Consultants who hold this view are comfortable letting their clients teach them things and see clients as sources of new knowledge.

Alternatively, more than half ( 52 percent) of consultants in this study did not expressly state that their clients taught them new things. Rather, they phrased it as taking away information from a project. The implicit tone was that, as experts, these consultants would not look at their clients as potential teachers. Yet in the course of their work, they did observe things or learn new things about the client's industry. One respondent said, "Sure, I learn from clients all the time. At the industry level you learn something about their work. But do they teach me things? No. You have to have the right mindset and have an inquisitive mind. If you don't go looking for it, you don't see it." A second respondent commented, "I'm one of those that always takes away from the experience. What I think I learn most from my clients is how many, how often at a senior level, they know extremely little or nothing at all about the industry." These consultants learned things about their clients' industries and business challenges during their engagements, but they do not view their clients as their co-teachers. As they see it, teaching is a one-way process from consultant to client.

\section{"We" versus "Me"}

In a related manner, consultants who used an empowering-expert strategy view themselves as mutually dependent on their clients. This concept is akin to a relationship-marketing approach, where the consultant seeks to create enhanced value for clients over time by learning about the client and customizing the product to meet clients' changing needs. ${ }^{23}$ One respondent who uses this strategy explained: "To me, the relationship is more important than the project. The projects will come and go, but the relationships should stay in place. I nurture my relationships. Before I moved to [this firm], I went to all of them and asked them, my handful of dear, long-term clients, how they felt about it, and if even one of them said 'no way, we won't follow you over there,' I wouldn't have gone. Because, as I said, the relationship is more important to me than anything." A second respondent said, "If you build the relationships, the services follow. My job is to keep giving my clients new ideas, new information. Twenty-five percent of the time, something hits. I have to be flexible and creative for them. They are my success." These consultants view themselves as dependent on their clients, and they work hard to ensure that their clients are satisfied with the relationship.

In a more-traditional view, 82 percent of responding consultants view themselves as completely or partially independent from their clients. They work with their client, and hope that their projects lead to additional work, but for the most part these consultants reported seeing themselves as the independent eye that moves from project to project, and from client to client. ${ }^{24}$ As

${ }^{23}$ L.L. Berry, "Relationship Marketing of Services: Growing Interest, Emerging Perspectives," Journal of the Academy of Marketing Science, Vol. 23 (1995), pp. 236-245; and M.J. Bitner, "Building Service Relationships: It's All about Promises," Journal of the Academy of Marketing Science, Vol. 23 (1995), pp. 246-251.

${ }^{24}$ While these data were collected prior to the recent ethical scandals that led to the collapse of one of the big-five accounting practices, the code of ethics outlined by the AICPA, the guiding institution for all CPAs, strongly and continually reinforces this independent perspective. 
EXHIBII ?

Service-delivery strategies

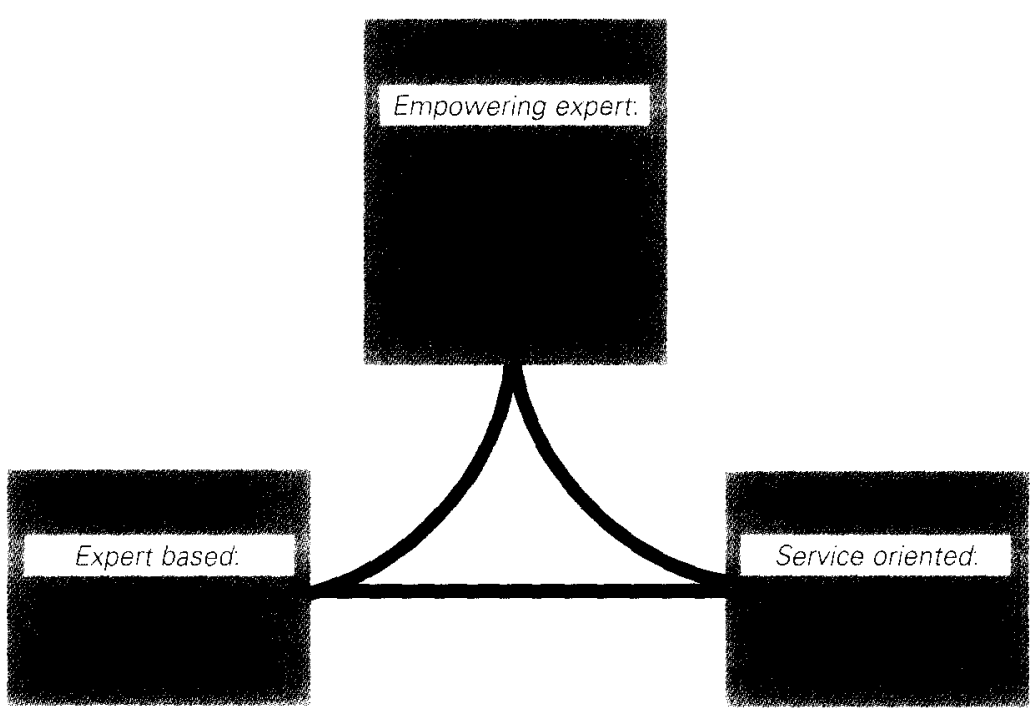

an independent third party who's an expert in a particular industry and we're viewed as part of due-diligence activities. ... The client wants to have that independent analysis come from a group like us." These consultants view their independent, objective opinion as critical to their work and their credibility. They do not think of themselves as dependent on their clients. Rather they see their clients as dependent on them for the credibility their firm name provides.

\section{Ask; Don't Tell}

Finally, the last distinguishing characteristic of an empowering-expert strategy is the way the consultant demonstrates expertise. Consultants who use this strategy tend to ask focused and careful questions and use listening skills as a strategy to discern a client's needs, and in doing so, demonstrate their knowledge. For example, one respondent mentioned how "my way of letting people know I'm an expert is by asking questions that are thought provoking, that make them know that I'm bringing something to the table because they wouldn't have even known to ask such questions." A second respondent said, "The good partner will take the time to figure out the client's needs, will ask lots of questions, and will spend lots of time listening to what's important to the client." Additionally, one respondent commented: "It's collaborative; it's me asking questions and then shutting up and hearing what the client has to say. That's how I help them."

Tell; don't ask. Alternatively, those who use an example, one respondent claimed: "In a lot of cases we'll end up with clients who aren't happy because they don't like the answer. We are a bigfive accounting firm, and we can't forget what the $\mathrm{P}$ in CPA stands for-the public-and the public is expecting that if our name is on the report that it's been looked at with the public in mind. Our credibility is critical there....You don't want to have too close a relationship with your clients. ...You need to remain as professional as possible." Similarly, another respondent said, "One of the more important qualities and skills a consultant should have is judgment, being able to make an informed, objective opinion. ... That's what I give clients. I've built my reputation around that." A third stated: "Clients hire us for the independent view. It's the concept of having more-traditional strategies generally demonstrate their expertise through telling and showing clients how much they know. Sixty percent of respondents reported using this approach, demonstrating their expertise by what they say and how they say it. For example, one respondent suggested: "It's important to have good presentation skills. ... How material is presented and how it's delivered is important to clients. ...Confidence is important, and you have to come at them, not with ego, but that you're confident. ...Approach is really important." Another said, "All of our clients are looking for experts, but if you can't get your point across both orally and in writing with that confidence then it's going to be useless to the clients. It's so important to be able to stand up in front of a crowd and sell the project, sell 
our clients, sell them that we're qualified to do the project." A third respondent said, "I explain and teach. But I have to stop if they get Bambi eyes. Then it's all over." In this more-traditional view, consultants show their expertise through telling, teaching, and selling.

\section{Differences in Strategies}

The difference between the empowering-expert strategy and the expert and service-oriented strategies is subtle yet critical. While those who think of themselves more as an expert also provide advice to help their clients succeed, these professionals concentrate more on providing the authoritative opinion that contributes to the success of their client's business. They are much less focused on making their clients personally succeed (and look like "heroes" to their boss or business group). Similar to those who use an empoweringexpert strategy, those who employ a serviceoriented strategy are also focused on providing attention and service to the client. Yet they are different in that they do not apply their expertise in such a focused and savvy manner. Instead, professionals who think of themselves as more service-oriented partners offer blanket attention and service.

These three service-delivery strategies can be thought of along an outcome-process continuum (see Exhibit 7). The focus of the expert-based strategy is on the outcome, that is, the results offered to clients. At the other end of the continuum, the focus of the service-orientedpartner strategy is on process. Somewhere in between those two, the focus of the empoweringexpert strategy is on using process to achieve the best outcome. Those who use that strategy combine process and outcome in such a way that they provide their clients with a highly customized service, specifically suited to each client's individual needs.

\section{Setting Expectations}

The differences in strategies found in this study suggest that hospitality decision makers would be wise to give thoughtful attention to the type of service they are seeking from the consultants they retain. Considerations include not only what decision makers expect from their consultants in terms of a finished product, but perhaps more
EXHIBIT 8

\section{Determining outcome and process expectations}

\section{Below are sample questions for decision makers to use in determining} their own needs from a consulting engagement.

(1) What do you expect from the finished product?

(2) How much do you already know about what this product should look like?

(3) What specifically is the scope of the work to be performed? How much is it outside your scope of expertise or knowledge?

(4) How customized does the final product need to be?

(5) How much input do you need to have? Want to have? How educated would you like to be on the topic?

(6) How involved do you want to be in this project? At what points (e.g., initially, at the midpoint, throughout)?

(7) How accessible are you? Your staff? At what times and by what means? How much are you willing to explain about your needs? How tolerant are you of clarifying questions?

(8) What do you expect from a consultant in terms of a final product? The way in which she (or he) delivers it?

(9) What sorts of output or behavior would be a deal breaker for you?

(10) Is this a one-time-only need, or is there the potential for you to work with this consultant or the firm on future engagements?

important, the role the managers expect themselves and the consultants they hire to play in the design and delivery of a contracted service.

Uncovering expectations. To aid in this decision-making process, Exhibit 8 outlines a series of questions for managers to consider when determining their expectations for consulting services. Granted, expectations change depending on the type of service contracted. Yet critical to the success of any consulting engagement is for clients to clearly articulate their expectations related to both the end-product and the process by which it is created. Too often, these expectations are implicit and assumed to be evident. As evidenced by this study, important differences exist in consultants' service-delivery strategies that, based on decision makers' expectations and preferences, will directly affect consultants' abilities to be successful.

Screening candidates. Once hospitality decision makers become clear about their own expectations regarding outcome, service delivery, and the connection between the two, they have a better tool kit with which to evaluate potential consultants. Questions such as those presented 


\section{EXHIBIT 9}

\section{Interview questions to guide choosing a consultant}

These questions are aimed at helping decision makers determine the approach a potential consultant is likely to use. Look for answers that focus on consultants' expertise, their service orientation, or some combination of both that helps decision makers personally succeed. Questions 3 and 6 aim at uncovering consultants' views and expectations about their clients. Changing the verbiage slightly, questions 5,6 , and 7 can also be used to interview previous clients about their satisfaction with a potential consultant.

(1) What do you see as the purpose of your work? What do you bring to the table?

(2) What do you think are the most important qualities and skills a consultant should possess?

(3) Describe how your typical engagement works

(4) How sophisticated and knowledgeable are your typical clients? How much hand-holding do they typically require?

(5) Why do you think your clients use your services-as opposed to another consultant's? What would your previous clients say makes you stand out from the rest?

(6) What is the typical way you've interacted with your previous clients? How often and by what forms (i.e., by email, phone, letter)? When are you most accessible?

(7) What do you expect from me? What, if anything, is my job?

\section{In addition, decision makers could also ask previous clients the} following questions.

(8) What type of service did you expect this consultant to perform? What did you expect in terms of a final product? What did you expect in terms of the way that she (or he) interacted and worked with you to deliver the final product? On a scale of 1 (low) to 5 (high), rate how well the consultant met your expectations.

(9) On a scale of 1 (low) to 5 (high), rate the level of sophistication of your project. Did performing it require a high level of expertise that few consultants are equipped to provide?

(10) Describe your level of involvement in this project. Was that level of involvement by your choice? How critical was your involvement to the final success of the project? Was this consultant able to respond to the level of involvement you wanted to have?

(11) Did you use this consultant before this project? If so, in what capacity? How responsive was she (or he) to your needs between projects?

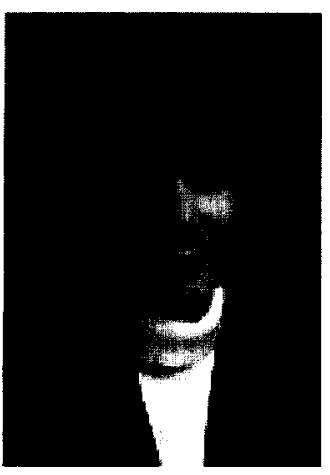

Kate Walsh, Ph.D., is an assistant professor of organizational management at the Cornell University School of Hotel Administration (kmw33@cornell.edu)

(c) 2002, Cornell University in Exhibit 9 can be used to uncover service professionals' different strategies. These questions prompt potential consultants to articulate the assumptions about themselves and the views of clients that underlie the ways they deliver their services.

In addition, these questions would be useful for discerning the extent to which previous clients of a prospective consultant were satisfied with the service performed. As well as uncovering previous clients' expectations and interpretations of the experience, these types of focused questions would enable decision makers to move beyond the general, "were you pleased with this consultant's services" to more fully understand the important reasons that underlie previous clients' satisfaction levels.

\section{A Barometer for Consulting}

The findings in this study can be used as a barometer of sorts for hospitality decision makers to think about their satisfaction with a consulting service. The types of strategies revealed through this study can help decision makers discern when they need more or less of an expertbased or service-oriented or empowering expert approach as consulting engagements evolve and the abilities of their consultants to employ these strategies. Ultimately, this framework can help hospitality decision makers understand on a deeper cognitive level the reasons behind their most successful consulting engagements, as well as their disasters, and long term, the type of approach that works best, given their unique needs and styles.

While other strategies to delivering an expertbased service likely exist, and while the role of fees and fee structure were not discussed as part of the decision-making process, this study offers hospitality decision makers ways to discern whether service professionals use an expert-based approach, a service-oriented approach, or an empowering-expert approach. By clarifying the differences among those strategies, hospitality decision makers can determine which approach is right for which project. Moreover, they now have better tools from which to select the "best fitting" service professional, one whose expertise and "final product" have the best chance of meeting and perhaps even exceeding expectations. 